\title{
Questions to the PM versus Questions by the PM: An Examination of the State and Nature of 'Punch and Judy' Politics during PMQs at Westminster.
}

\author{
Mark Peter Shephard, Daniel Braby
}

We know about what the public thinks of PMQs, and we know an increasing amount about questions to PMs. However, very little is known about the nature and state of questions that the PM asks during the procedure. Controlling for the average length of PMQs, we find that while the average number of Order Paper questions reached has stayed relatively static, the total number of questions asked has nearly halved over time while questions asked by the PM (including questions levelled at both the Leader of the Opposition and the opposition) have increased over time. We also find that specific blaming by the PM of the previous government is far higher right after party rotation in government (Blair and Cameron) than after PM rotation intra-party government (Brown and May). Finally, we find that Cameron was significantly more likely to ask questions during PMQs when this correlated with higher public opinion net approval ratings.

'...like a fight over a bag of boiled sweets in a boys' school playground, circa $1950 \ldots$..PMQs is puerile, point-scoring, yah-boo nonsense, which has done more to debase the reputation of politicians than anything else - and that includes spin doctors, leaked emails and fiddled figures' (Ashley, 2002)

'Prime Minister's Questions should be for the PM to be able to answer what the government's policies are not for point-scoring' (Allen et al., 2014: 31)

Irrespective of viewpoint on PMQs, what occurs during PMQs is of high salience as it is the most well-known and viewed parliamentary procedure by the general public. Indeed, survey evidence has shown that more than half of the general public report having watched or heard PMQs in the last 12 months (Hansard Society, 2014: 65). This degree of accessibility to political debates between leaders is important as comparative research indicates that countries with open parliamentary question times are associated with higher levels of knowledge, partisanship and turnout (Salmond, 2014a). Moreover, aside from the agreement of recent PMs to appear occasionally before the Liaison Committee (2002-), the introduction of PMQs in the 1960s, is one of the limited number of procedural changes that has helped stem an otherwise notable decline in the direct accountability of the PM to Parliament (Dunleavy et 
al., 1993). However, just because there is a regular parliamentary procedure for the questioning of the PM does not necessarily mean that it works well in practice. In terms of public perception, the vast majority of those who have watched or heard PMQs think that there is too much party-political point-scoring instead of the answering of questions (Hansard Society, 2014: 71). One specific Hansard Society (Allen et al., 2014) report on the state of PMQs based on extensive focus group research with the public found quite negative attitudes towards the procedure, for example:

'I don't think it serves any purpose any more - it is supposed to hold the PM to account but now it is just a pantomime' (Allen et al., 2014: 5)

'...the PM refusing to answer simple yes or no questions...' (Allen et al., 2014: 5)

'...a pathetic spectacle'...MPs 'just seem to be point-scoring and not really thinking' (Allen et al., 2014: 5)

In assessing what needs to change, Allen et al. (2014) found that most participants wanted to eradicate the petty point-scoring (2014: 32) behaviour referred to by David Cameron as 'Punch and Judy' politics. Indeed, Cameron is on record as saying how much he lamented 'Punch and Judy' politics and how he wanted to get rid of this kind of behaviour. In his victory speech for the leadership of the Conservative Party Cameron stated:

'...we need to change, and we will change the way we behave. I'm fed up with the Punch and Judy politics of Westminster, the name calling, backbiting, point scoring, finger pointing' (David Cameron, quoted in The Guardian, 6 December 2005).

However, in a January 2015 YouGov survey, 79 percent of the public thought that David Cameron had not managed to rid Westminster debates of 'Punch and Judy' politics. Lovenduski (2012) also found that female MPs would prefer more substantive discussions to confrontational argument during PMQs. Allen et al. (2014) are also concerned about the operation of PMQs and argue that for parliament to repair its reputation it needs to address four key areas: being out of touch; bad behaviour; questions over format and effectiveness; and a perceived lack of accountability (2014: 9). Even more damning is the view that the partisan battle of the chamber means that PMQs should be dismissed as an effective means of holding the Prime Minister to account (Bennister and Kelso, 2015). 
While measures of poor behaviour in PMQs have previously been assessed (see for example, Shephard 1999 and Bates et al. 2014) attempts to quantify and evaluate the quality of replies (Bates et al., 2014) have not yet identified the extent to which each PM has used the procedure to counter-question the opposition per se. Though Bull and Strawson (2019) identify counter-questioning in their analysis of equivocation by the PM, this is limited to 23 sessions of PMQs with a focus on interaction between the two main party leaders (May and Corbyn). However, concerns over counter-questioning by the PM precede May. As David Cameron lamented during his very first appearance at PMQs as Leader of the Opposition:

'It is only our first exchange, and already the Prime Minister is asking me the questions. This approach is stuck in the past, and I want to talk about the future. He was the future once.' (David Cameron, Hansard, 7 December 2005, Col. 862)

On the positive side, there is some evidence that those who watched or heard PMQs in full are more likely to find it informative, exciting, and are less likely to be put off politics than those who only watched or heard clips in part or not at all (Hansard Society, 2014: 70). Such findings add credence to those such as Salmond (2014b) who argues that it is better to have higher engagement (for example, voting) and antipathy towards leaders than it is to have lower engagement and a more sanguine view of leaders (2014b). However, how can parliament aid in achieving both higher engagement and a more positive perception of leaders? Perhaps if the behaviour of both MPs and the PM were not so 'yah-boo', and reflective of 'party political point-scoring', interest, engagement and a better view of politicians themselves could be achieved.

One poll by YouGov (2015) controlling for respondent's age, found that those aged over 40 were much more likely to view the standard of debate in the Commons as 'loud, aggressive, and childish' than those under the age of 40. Interestingly, Cumberbatch et al. (1992), Shephard (1999), and Bates et al. (2014) find that the number of interruptions during PMQs has increased over time. What is not yet fully explored is the extent to which 'Punch and Judy' politics has altered over time, particularly from a quantitative assessment of the workings of the procedure. Given findings which indicate that personal attacks among central figures in PMQs have increased over time (Waddle et al. 2019), it suggests that we should expect that 'Punch and Judy' point-scoring behaviour will have increased over time. Interruptions have increased, and the older public is more dismissive of the behaviour in 
Westminster than the younger generations, possibly suggesting that they are aware that behaviour has got worse over time. However, as well as measuring interruptions, we need other measures and ways to decipher if behaviour has worsened over time, or if the older members of the public are viewing the past through rose-tinted spectacles.

Consequently, there is much commentary and public opinion out there on how poor Prime Minister's Questions (PMQs) is, and yet little systematic data examines how true these statements are, and how things have changed over time. This paper starts to address the paucity of data on 'Punch and Judy' style point-scoring during PMQs by counting the number of questions asked by both MPs and the PM (contrasting the experiences of Blair, Brown, Cameron and May). The target and intent of PM questions are further assessed to ascertain the degree to which PMQs is as much about questions to the opposition by the PM as it is questions to the PM. It also measures the apportionment of blame placed by the PM on the previous government, as well as general critique of the opposition in response to their questions. Finally, we explore the relationship between net public opinion ratings of the PM with PM behaviour during the procedure.

Controlling for the average length of PMQs, we find that while the average number of Order Paper questions ${ }^{i}$ reached has stayed relatively static, the total number of questions (including: supplementary questions ${ }^{\text {ii }}$; questions formally granted to opposition leaders; and those granted to members at the discretion of the speaker) asked has nearly halved over time while PM questions (including questions levelled at both the Leader of the Opposition and the opposition) have increased over time. We also find that specific blaming by the PM of the previous government is far higher right after party rotation in government (Blair and Cameron) than following PM rotation intra-party government (Brown and May). Finally, we find that Cameron was significantly more likely to ask questions during PMQs, the higher his public opinion net approval ratings.

\section{The state of the literature on PMQs}

There has been increasing interest in PMQs in academic literature, reflected by the variety in explorations and examinations of the procedure. One of the first exploratory qualitative studies of impolite behaviour during PMQs found much of the procedure to be comprised of 
intentional and explicit face-threatening acts (Harris, 2001). Bull and Wells (2012) built on Harris' work and developed a conceptualisation of face threats and face managements used by the PM and the Leader of the Opposition. They identified six distinctive ways in which the Leader of the Opposition performed face-threatening acts (proposition which prefaces an interrogative; detailed question; contentious presupposition; conflictual question; invitation to perform a face-damaging response; and aside) and five distinctive ways in which the PM countered such acts in replies (talk up positive face; rebut; attack; ignore; and selfjustification).

Murphy (2014) has subsequently analysed the incidence of 'face-threatening acts' by both MPs and the PM during six PMQs (three from Brown's premiership and three from Cameron's), and found that impoliteness was very much a feature of opposition MP questions, while the PM will typically only be impolite in response to impoliteness. Controlling for issue, further research by Waddle and Bull (2019) has revealed that personal attacks by both the PM and the Leader of the Opposition are higher on domestic issues than they are for foreign policy issues. That said, it does appear that behaviour overall has worsened over time. Waddle et al. (2019) measured personalised attacks during the first and last 10 PMQs between the PM (Thatcher to Cameron) and the Leader of the Opposition and found that all PMs (except Blair) were more disrespectful than their predecessors. They also found that, from 1979 until the general election of 2015, personal attacks by Leaders of the Opposition were higher in the later periods of all premierships other than Blair's.

Studies have also analysed the degree to which a PM answers the questions set to them during PMQs. Albeit limited to the analysis of one PM, Bull and Strawson (2019) found that May's mean rate of reply to questions from Labour leader Jeremy Corbyn during her first year as PM was just $11 \%$. Their study explored ways in which the PM equivocates when faced with a question and found that common strategies included: ignoring; modifying; stating that she had already answered a question and acknowledging questions without answering them.

In a study including data from Thatcher to Cameron, Bates et al. (2014) found that the average number of questions reached declined after Thatcher in large part due to the increase in interruptions, as well as the rise of supplementary questions granted to the Leader of the 
Opposition - for the latter point, see work by Giddings and Irwin (2005). Bates et al. (2014) also engaged in qualitative research and found that non-replies to questions were lowest for Blair and Cameron, although when they control for the difficulty of the question, Thatcher and Brown were found to provide the fullest answers.

There has also been an extensive examination of the issues raised during PMQs. Bevan and John (2016) found that opposition MPs are effective in using the procedure to raise issues most likely to cause discomfort to the government, for example, the economy and defence. They find that this then sets the agenda for the topics that government backbench MPs raise. Moreover, the opposition set the agenda more than the government backbench MPs.

Other studies have examined the rise in the ratio of open questions to substantive questions over time (Irwin et al., 1993; and Shephard, 1999); the attendance rates of PMs over time (Shephard, 1999; and Kelly 2015); the rise in questions tabled post-cameras (Borthwick, 1993); the rise in partisanship post-cameras (Franklin and Norton, 1993; and Shephard 1999); and the rise in combativeness (Burnham et al. 1995); the roles of the Leader of the Opposition (Alderman, 1992); topics covered by the questions of the Leader of the Opposition (Griffith and Ryle, 1989) and by all MPs (Bates et al., 2014). There have also been broader studies of the PM examining quantitative counts of prime ministerial activities in the House (Dunleavy et. al. 1990 and 1993) as well as an examination of the roles and functions of questions (see for example, Chester and Bowring 1962; Franklin and Norton, 1993; Norton, 1993; Wiberg, 1994; Shephard, 1999; and Martin, 2011 and 2013).Finally, Bull and Waddle (2019a) have explored the extent to which PM reply rate and personalisation vary according to whether the Leader of the Opposition posits a question connected to a member of the public ('Marie asks...'). They found that personal attacks were lower on those questions that named a member of the public, but that PM reply rates showed no improvement.

One thing that is not controlled for in the comparative literature on PMs during PMQs, is the increased length of each occurrence. Whereas PMQs would last for approximately 30 minutes under Blair, average duration slowly crept up under Brown and Cameron and then increased quite noticeably under May. 
As well as controlling for variance in duration of the procedure, our study aims to add to the body of existing work on PMQs to date by further exploring the dynamics of PMQs as a platform for both questions to and from the PM. The content of questions raised by the PM was further studied to gauge the extent that the PM uses counter-questioning as a platform for criticism of both previous governments and current opposition. While the existing literature has provided some qualitative categories for types of PM counter-attack behaviour (see Bull and Wells, 2012) and for incidence of questioning the question (see Bull and Strawson 2019), we are interested in quantitatively accounting for the variance in the incidence of PM questions by exploring the dynamic relationship between the relative power of the PM at any one time and the incidence of their questioning behaviour.

Fast et al. (2012) have found that feeling powerful exacerbates overconfidence in own knowledge and subsequent risk-taking and under-performance. Pfeffer (2010) has made similar observations and also argued that those in power often suffer from insensitivity to others. Keltner et al. (2003) have also found that powerful people feel fewer constraints on their behaviour and Anderson and Galinsky (2006) have observed that those individuals primed with a high-power mindset are more likely to engage in risk-taking behaviour. Finally, Maner et al., (2007) have found that when one's power is strong, people engage in risk-taking, but when the status quo is perceived to be in jeopardy, those in power tend to engage in more conservative behaviours. Consequently, we hypothesise that when the net public opinion approval ratings for PMs are higher (granting the PM more validation, legitimacy, and security in power), we might expect less inhibited and more confident displays at questions manifesting in behaviour such as asking questions of the opposition. Conversely, when net public opinion approval is low, we might expect the PM not to be as confident in questioning back and blaming the opposition. We also expect, that if the existing literature is right (see for example, Waddle et al., 2019), behaviour during PMQs will have declined over time and so we should expect the incidence of PM questions, blame, and critique, all to have risen over time.

\section{Methods}

Following the same logic as Bates et al. (2014), we study comparable PMQs from the start of premierships, using transcripts recorded and published by Hansard. Going further than Bates 
et al. (2014), for most measures, we go beyond the first ten sessions of PMQs and measure up to a year's activities from election victory to the following year's second session. ${ }^{1}$ Data are for new incoming PMs, two representing an inter-party change of PM and government (Blair and Cameron), and two representing an intra-party change of PM (Brown and May).

For Blair, the total number of PMQs per first parliamentary session (or first year comparable equivalent in the case of Cameron) was double that for May, and noticeably higher than for Cameron and Brown. Meanwhile, comparative attendance by the PM has been quite high, and highest for both Blair and May (see Table 1).

Table 1: Total Number of PMQs

\begin{tabular}{|c|c|c|}
\hline & $\underline{\text { PMQs - Total N }}$ & PMQs with PM present - Total N (\%) \\
\hline Blair (05/97-10/98) & 50 & $49(98 \%)$ \\
\hline Brown (07/07-07/08) & 36 & $34(94 \%)$ \\
\hline Cameron $(06 / 10-07 / 11)$ & 41 & $38(93 \%)$ \\
\hline May (07/16-04/17) & 25 & $24(96 \%)$ \\
\hline
\end{tabular}

As well as counting questions that were reached on the Order Paper, we also count the total number of all questions asked, using a search of the incidence that '?'was recorded, irrespective of the number of contributors. The total number of all questions ('?') asked also includes questions that are asked by the PM, which we also treat and count as a separate variable. We then provide a qualitative assessment that parses the questions asked by the PM into three groups: 1) those that ask questions of the opposition; 2) the subset of 1) that are specifically directed at the Leader of the Opposition; and 3) other, for example, 'may I send my condolences to...?' (see Appendix 1 for specific examples of coding types).

To assess the nature of 'political point-scoring' (Allen et al. 2014) in Prime Minister's Questions, the apportionment of the blame levelled on previous governments and general criticism of the Opposition in Prime Minister's counter questions were also coded

\footnotetext{
${ }^{1}$ Given that the first session of parliament for David Cameron spans two years, the first sessions for Blair, Brown and May are contrasted with a more comparable $\mathrm{N}$ that includes cases for the first year of Cameron. The 2016-2017 parliamentary session is a little under a year due to the early 2017 General Election.
} 
adopting a standard 'first ten' PMQs sampling approach used by much of the literature (see Bates et al. 2014). The apportionment of blame levelled on previous governments for both questions intended for a response, or not, were identified by either direct reference (party/leader/senior figures named) or indirect reference (issue, often relating to budget deficits) of failures by a former government. General criticisms of the Opposition were singled out by forms of personal attack (Waddle et al. 2019), references to regional branches or declarative questions regarding a lack of or fault in Opposition policy alternatives.

Appendix 2 provides specific examples of coding types by the PM in replies to questions by the main Leader of the Opposition of each of the four PMs: Blair (21/05/97 to 30/07/97); Brown (04/07/07 to $16 / 07 / 08)$; Cameron (02/06/10 to 20/10/10 controlling for two absences by taking the first ten PMQs that Cameron was himself present); and May (20/07/16 to 10/11/2016).

To explore the dynamics between the status and power of the PM and the extent to which the PM asks questions, we examine the correlation between net public opinion approval ratings of the PM and questions raised by the PM. Net public opinion approval ratings come from IPSOS MORI and measure percent approving of the PM minus percent disapproving of the PM. Each net approval public opinion percentage recorded for each incidence of PMQs reflects the latest figure that would have been public knowledge at the time of each PMQs.

Since Blair, PMQs are intended to be 30-minute long weekly events. However, under Speaker of the House, John Bercow, they have in recent years tended to run quite a bit over the approximate 30-minute original schedule that operated under Blair. To control for the considerable variance in duration, we present findings with and without word count weighting. By weighting the data by word count, we introduce the first study of PMQs to control for variance in findings that may, in fact, be due to variance in the duration of the procedure; this is particularly important for the much longer sessions of PMQs during May's first year compared with those of Blair and Cameron.

Finally, we perform both blind intra-coder and blind inter-coder reliability checks on our counts for a ten per cent sample of our data. Using Cohen's Kappa (k) we control for the capacity to find the same result by chance. Kappa statistics range from -1 (complete disagreement) to +1 (complete agreement). Our Kappa statistics for the data we present in this paper range from 0.76 to 1.0 indicating high levels of agreement/consistency for both the 
main coder at the initial code (time 1) and at the second-run of this coding (time 2), and between the main coder and the checker of the main coder.

\section{Results}

Calculating word count averages for each of the first parliamentary sessions (*see Table 2) of the four PMs reveals that with each subsequent PM, the average length of each PMQs increases over time. The average number of words used rises from a low of 4,045 words under Blair to a high of 6275 words for May (see Table 2). In turn, we argue that it is essential to weight findings according to the length of each PMQs; otherwise we might overstate the presence or absences of behaviours per PM relative to the duration of the procedure.

Table 2: Average number of words per First Session of Parliament* of PMQs

$\underline{\mathrm{PM}}$ Average Number of Words per PMQs (N)

Blair 4045

Brown 4391

Cameron 4700

May

6275

Note: Data are for all PMQs, including those when the PM is not present. Differences in means between when the PM is and is not present are not significantly different. *For comparability. We measure the first year for Cameron as the first parliamentary session was two years (2010-2012) in duration.

The average number of Order Paper questions reached per PMQs has increased with each subsequent Prime Minister (see Table 3a). On average approximately 11 Order Paper questions were reached under Blair and Brown, while approximately 14 were reached under Cameron and May. The ranges in questions reached per PM are noticeably different for May compared with her three predecessors. Order Paper questions reached ranged from a low of 5 to a high of 16 under Blair, from 7 to 15 under Brown, from 9 to 15 under Cameron, while 
for May the range is both minimal and high in number, from 12 to 15 . The quite marked differences between May and her former three predecessors can be explained in large part by the average length of the procedure reflected in the total mean word counts. Indeed, Speaker John Bercow's preference for a 45-minute PMQs over a conventional 30-minute time slot had come into standard practice by the time of Theresa May's premiership, and this is reflected in the average word counts per PMQs per PM (see Table 2).

Table 3a: Average Number of Questions Asked

per First Parliamentary Session* of PMQs

\begin{tabular}{|c|c|c|c|c|}
\hline$\underline{\mathrm{PM}}$ & $\underline{\text { Order Paper Qs }}$ & $\underline{\text { Total Qs }}$ & Qs by PM & Qs by PM/Total Qs (\%) \\
\hline Blair & 10.68 & 43.74 & 1.42 & $3.2 \%$ \\
\hline Brown & 11.25 & 39.42 & 1.92 & $4.9 \%$ \\
\hline Cameron & 13.85 & 39.98 & 4.54 & $11.4 \%$ \\
\hline May & 14.52 & 40.32 & 2.88 & $7.1 \%$ \\
\hline
\end{tabular}

Note: Data are for all sessions of PMQs, including those when the PM is not present. Differences in means between when the PM is and is not present are not significantly different. *For comparability, we measure the first year for Cameron as the first session of parliament was two years (2010-2012) in duration.

While the average number of Order Paper questions reached was lowest for Blair, the average number of questions asked ('?') irrespective of Order Paper questions, and supplementary questions are noticeably higher under Blair per PMQs than it is for Brown, Cameron, and May. On average, nearly 44 questions ('?’) are asked under Blair per PMQs compared with approximately 40 for Brown, Cameron and May (see Table 3a). Given that the length of May's PMQs is typically 15 minutes longer than her three predecessors, all things being equal, we might expect the higher average to lie with May and not Blair.

Focusing on the behaviour of the four PMs, the average number of questions posed by each PM is noticeably higher for the later Conservative PMs than it is for the earlier Labour PMs (see Table 3a); this also holds if we examine the proportion of total questions that originate 
from the PM. On average, Cameron asked nearly five questions per PMQs (over 11 percent of the total) compared with just over one question per PMQs for Blair (just over three percent of the total).

Given the differing average word count totals of PMQs under each PM, Table $3 b$ reports weighted data that averages the number of questions asked per 1000 words. While contrasting weighted data (Table 3b) with unweighted data (Table 3a) reveals less variance in the number of Order Paper questions that are reached, while the total number of questions ('?') asked have declined noticeably with each subsequent PM. Indeed, from Blair to May there is almost a halving of the number of all questions (see Table 3b). Under Blair, there are approximately eleven questions, compared to just over six for May. Finally, questions that the PM asks shows that David Cameron asked more than twice as many questions than Blair, Brown, and May.

Table 3b:

Average Number of Questions Asked per 1000 Words per First Session of Parliament* of PMQs

\begin{tabular}{lccl}
\hline$\underline{\text { PM }}$ & Order Paper Qs & Total Qs & Qs by the PM \\
Blair & 2.64 & 10.81 & 0.35 \\
Brown & 2.56 & 8.98 & 0.44 \\
Cameron & 2.95 & 8.51 & 0.97 \\
May & 2.31 & 6.43 & 0.46 \\
\hline
\end{tabular}

Note: Data are for all PMQs, including those when the PM is not present. Differences in means between when the PM is and is not present are not significantly different. *For comparability, we measure the first year for Cameron as the first session of parliament was two years (2010-2012) in duration.

We then disaggregated the qualitative content of questions asked by the PM during their first ten PMQs to examine the degree to which questions are levelled at the Leader of the Opposition (LO) and the opposition excluding the LO (O). We find that the average number of questions asked by the PM are noticeably higher for the two Conservative PMs (Cameron and May) compared with the two Labour PMs (Blair and Brown). Controlling for those questions asked by the PM that are levelled directly at the Leader of the Opposition, we find 
that Cameron and May again exceed Blair and Brown in this behaviour (see Table 4a). If we combine the findings for the Leader of the Opposition with those for the opposition (excluding the Leader of the Opposition) we find the same thing, Cameron and May are more prone to asking questions of the opposition.

Table 4a: Average Number of Questions Asked per PMQs*: All Qs by the PM vs. Questions Targeting Leader of Opposition (LO) vs. Questions Targeting Opposition (O)

\begin{tabular}{|c|c|c|c|c|}
\hline$\underline{\mathrm{PM}}$ & Qs by the PM & \multicolumn{2}{|c|}{ Qs by the PM to LO (\%) } & Qs by the PM to O (\%) \\
\hline Blair & 1.60 & 0.10 & $(6.3 \%)$ & $1.00(62.5 \%)$ \\
\hline Brown & 0.90 & 0.60 & $(66.7 \%)$ & $0.30(33.3 \%)$ \\
\hline Cameron & 5.60 & 2.90 & $(51.8 \%)$ & $1.50(26.8 \%)$ \\
\hline May & 3.10 & 1.10 & $(35.48 \%)$ & $0.60(19.4 \%)$ \\
\hline
\end{tabular}

Note: *Data are for the first ten PMQs fronted by each PM (skipping those cases where the PM was absent). Percentage figures are in proportion to Qs by the PM totals and may not add up to $100 \%$ as some Qs by the PM are not directed at either the Leader of the Opposition or the opposition (excluding the Leader of the Opposition).

However, we need to control for the variation in PMQs duration per PM, and so Table $4 \mathrm{~b}$ presents the weighted findings averaged per 1000 words. Controlling for the length of the procedure makes Cameron stand out as more of an outlier higher questioner than the other three PMs, although both Conservative PMs (Cameron and May) still ask more questions compared with Blair and Brown. Moreover, the proportion of PM questioning of the Leader of the Opposition has increased noticeably post-Blair, again with Cameron and May in the lead. If we combine the PM question findings for the Leader of the Opposition with those for the opposition (excluding the Leader of the Opposition) we find that while Cameron asks approximately one question of the opposition per 1000 words on average, the average for May and Blair is one for every 3571 words, while Brown is one for every 4762 words. 
Table 4b: Average Number of Questions Asked per PMQs* per 1000 Words: All Qs by the PM vs. Questions Targeting Leader of Opposition (LO) vs. Questions Targeting Opposition (O)

\begin{tabular}{|c|c|c|c|}
\hline$\underline{\mathrm{PM}}$ & Qs by PM & Qs by the PM to LO & Qs by the PM to O \\
\hline Blair & 0.40 & $0.02(5.0 \%)$ & $0.25(62.5 \%)$ \\
\hline Brown & 0.21 & $0.14(66.7 \%)$ & $0.07(33.3 \%)$ \\
\hline Cameron & 1.19 & $0.62(52.1 \%)$ & $0.32(26.9 \%)$ \\
\hline May & 0.49 & $0.18(36.7 \%)$ & $0.10(20.4 \%)$ \\
\hline
\end{tabular}

Note: *Data are for the first ten PMQs fronted by each PM (skipping those cases where the PM was absent). Percentage figures are in proportion to Qs by the PM totals and may not add up to $100 \%$ as some Qs by the PM are not directed at either the Leader of the Opposition or the opposition (excluding the Leader of the Opposition).

In addition to questions posed by the PM to the opposition, the first ten PMQs of each PM were analysed to see how many PM questions on average relate to blaming the previous government (see Table 5a). The first noticeable difference between the PMs is that those PMs replacing the main opposition party in government (Blair in 1997 and Cameron in 2010) are keener to both blame past governments than Brown and May who succeed governments of their own party. Meanwhile, critiquing of the opposition has become slightly more prevalent with each successive PM. Compared with Blair, Cameron was more than twice as likely to blame past governments per PMQs and three times as likely to critique the opposition (see Table 5a). Controlling for the duration of PMQs (see Table 5b) we still find that Blair and Cameron are more likely than Brown and May to blame past governments and that critique of the opposition has more than doubled for the PMs since Blair. 
Table 5a: Average Number of Questions Asked per PMQs*: All Qs by the PM vs. Blaming Previous Government (BPG) vs. Critiquing Opposition (CO)

\begin{tabular}{|c|c|c|c|c|}
\hline$\underline{\mathrm{PM}}$ & Qs by the PM & \multicolumn{2}{|c|}{ Qs by the PM BPG (\%) } & Qs by the OM CO (\%) \\
\hline Blair & 1.60 & 1.00 & $(62.5 \%)$ & $0.20(12.5 \%)$ \\
\hline Brown & 0.90 & 0.30 & $(33.3 \%)$ & $0.40(44.4 \%)$ \\
\hline Cameron & 5.60 & 2.50 & $(44.6 \%)$ & $0.60(10.7 \%)$ \\
\hline May & 3.10 & 0.00 & $(0.0 \%)$ & $0.70(22.6 \%)$ \\
\hline
\end{tabular}

Note: *Data are for the first ten sessions of PMQs fronted by each PM (skipping those cases where the PM was absent). Percentage figures are in proportion to Qs by the PM totals and may not add up to 100\% as some Qs by the PM are not directed at either the Leader of the Opposition or the opposition (excluding the Leader of the Opposition).

Table 5b: Average Number of Questions Asked per PMQs* per 1000 Words: All Qs by the PM vs. Blaming Previous Government (BPG) vs. Critiquing Opposition (CO)

PM Qs by the PM $\quad$ Qs by the PM BPG Qs by the PM CO

$\begin{array}{llll}\text { Blair } & 0.41 & 0.26(63.4 \%) & 0.05(12.2 \%) \\ \text { Brown } & 0.22 & 0.07(31.8 \%) & 0.09(40.9 \%) \\ \text { Cameron } & 1.22 & 0.55(45.1 \%) & 0.13(10.7 \%) \\ \text { May } & 0.50 & 0.00(0.0 \%) & 0.12(24.0 \%)\end{array}$

Note: *Data are for the first ten sessions of PMQs fronted by each PM (skipping those cases where the PM was absent). Percentage figures are in proportion to Qs by the PM totals and may not add up to $100 \%$ as some Qs by the PM are not directed at either the Leader of the Opposition or the opposition (excluding the Leader of the Opposition). 
Finally, Table 6 reports the correlation between net public opinion approval of the PM and the total number of questions asked by the PM. To recall, we expected the PM to be less inhibited and more confident (for example, the PM asking questions) when public approval of the PM was higher. Support for our findings was limited to just one of the four PMs. While asking questions during PMQs does not appear to be significantly correlated to public opinion approval for, Blair, Brown and May, we find that Cameron was significantly more likely to ask questions during PMQs when his approval ratings were higher.

Table 6: Correlation Between Net Public Opinion Approval of the PM

and the Total Number of Questions by the PM

PM Qs by the PM v. Net PM Approval Number of Cases

$\begin{array}{lll}\text { Blair } & 0.02 & (49) \\ \text { Brown } & -0.18 & (34) \\ \text { Cameron } & 0.39 * & (38) \\ \text { May } & 0.17 & (24)\end{array}$

Note: Data uses IPSOS MORI net public opinion approval ratings of the PM known at the time of PMQs. Data excludes the odd occasion when the $\mathrm{PM}$ is absent. ${ }^{*} \mathrm{P}<0.01 * \mathrm{P}<0.05$.

\section{Conclusion and Implications}

We make several main contributions to the growing literature on PMQs in this paper. First, we control for the average length of each session of PMQs as counts alone may say more about the varying lengths of a session of PMQs over time than differences in behaviour across PMs. Second, we extend measurements for when PMQs is being used by the PM to ask questions and view this in proportional terms relative to the number of overall questions. Third, we explore the dynamics of target and intent of questions raised by the PM and measure the extent to which PM questioning corresponds with PM net public opinion ratings. 
We find that PMQs have lengthened with each PM, but that duration has increased considerably under PM May (approximately a third longer than for Cameron, Brown, and Blair). While the average number of Order Paper Questions has increased under Cameron and May (compared with Blair and Brown), once we control for different lengths of PMQs, the number of such questions reached is reasonably constant, albeit suggestive of a slight decline in number for May. Moreover, when the data is weighted to account for the average length of PMQs, the total number of questions that are asked during each PMQs has almost halved from Blair to May, while the proportion of questions asked by the PM in relation to the total number of questions asked has more than doubled. Indeed, questions levelled by the PM at the opposition are notably higher under Cameron and May than they are under Blair and Brown. This finding adds further concern to the declining accountability thesis of Dunleavy et al. (1993) as while PMQs may have stemmed the decline in opportunities to question the PM, increased incidence of questioning by the PM is challenging the very raison d'etre of the procedure.

As might be expected, we find that PM blaming of the opposition is higher right after party rotation in government (Blair and Cameron) than following PM rotation intra-party government (Brown and May). Exploring the relationship between net public opinion approval and the incidence of questions raised by the PM reveals mixed results: Cameron appeared buoyed and bullish in the use of questions when his approval was high whereas the other three PMs experienced no significant correlations between the incidence of PM questions and public approval. Findings that Cameron was more prone to adversarial behaviour are consistent with those of Waddle et al. (2019).

Our findings suggest that far from trying to end 'Punch and Judy' politics, Cameron was more likely to ask questions of the opposition, and more likely to blame and critique the opposition than either Blair, Brown, or May. Given that much of the counter-questioning and blaming of the opposition by the PM post-Blair occurs in response to Opposition Leader questioning, perhaps the procedure needs revising to free up more time for backbench questioning. If implemented it may well result in the pantomime bickering of the Commons going down while maintaining higher engagement (in line with Salmond, 2014a) and yet encouraging a more sanguine view of leaders (contrary to Salmond, 2014b). Our findings here add evidence and weight to those of Norton (1993) and Allen et al. (2014) who have 
also advocated granting less time for the Opposition Leader and more time for backbench questioning of the PM.

Of course, one caveat here is our measurement of questioning. While we do account for qualitative differences in the types of questions that a PM asks, we are still basing this upon an initial find and count of '?' during a PM reply. To the extent that this is 'a' measure of questioning and not 'the' measure of questioning, this raises issues of measurement and internal validity. One solution to this would be to share our data and merge our approach with that of others such as Bull and Strawson (2019) so that we can more acutely measure this.

Another caveat is that our findings may say more about the context of politics, leadership style, and/or the interplay of parties and leaders and genders at a particular time. The addition of further cases and time periods would be useful for future research on this. One recent development under Boris Johnson has been to create a parallel procedure called People's PMQs in which the PM responds to questions received by the general public. While this development looks like an extension of opportunities for PM scrutiny, it has arguably been at the expense of time that could have been given to Parliament (for example, on Brexit debates). More seriously, with People's PMQs the PM chooses the questions to respond to and there is no reply option for the public.

Aside from People's PMQs, should the public and parliamentarians be worried about the state of PMQs? Perhaps we should be worried about the rise of interruptions (see Shephard, 1999; and Bates et al. 2014) and the rise of 'Punch and Judy' politics we find in this paper, but as Packenham (1970) notes in his typology of legislative functions derived from his study of the Brazilian National Congress, there are multiple functions that legislatures fulfil. Legislatures are not just about scrutiny of the executive; they also carry out other functions such as the representation of party, groups, and constituency interests. There is also the critical role of tension release (Packenham, 1970; and Norton , 1993), so heated arguments and exchanges are executed inside the legislature rather than on the streets. PMQs arguably provides an essential vent for tensions, even under the new less combative regime attempted by Corbyn. Indeed, within minutes of the 'new order' under the first Cameron/Corbyn PMQs, members of the opposition had interrupted the PM, and this continued in their subsequent encounter at the next PMQs. Consequently, when legislative procedures come under review, it is essential to consider not just the scrutiny of the executive, but the extent to which 
broader functions of legislatures are fulfilled. Otherwise, revised procedures that improve some functions while suppressing others without due consideration for the broader consequences on the polity may produce unintended and deleterious consequences.

Word Count (main text excluding references and appendixes): 6779

Word Count total: 9213 


\section{References}

Alderman, R. K. (1992) 'The Leader of the Opposition and Prime Minister's Question Time', Parliamentary Affairs, 45 (1), 66-76.

Allen, B., Fox, R., Geis-King, I., Gibbons, V., Korris, M., Pavlova, P. and Raftery, M. (2014) Tuned In or Turned Off? Public Attitudes to Prime Minister's Questions (London: Hansard Society).

Anderson, C., and Galinsky, A. D. (2006) 'Power, Optimism and Risk-Taking', European Journal of Social Psychology, 36 (4), 511-536.

Ashley, J. (2002) 'No Question: Scrap PMQs', The Guardian, 18 July 2002, http:/www.theguardian.com/politics/2002/jul/18/houseofcommons.politicalcolumnists1 (date accessed: 21 July 2015)

Bates, S. R., Kerr, P., Byrne, C., and Stanley, L. (2014) 'Questions to the Prime Minister: A Comparative Study of PMQs from Thatcher to Cameron', Parliamentary Affairs, 67 (2), 253280 .

Bennister, M. and Kelso, A. (2015) 'Prime Ministerial Accountability to Parliament', 10 May 2015, http://britishpoliticsgroup.blogspot.co.uk/2015/05/prime-ministerial-accountabilityto.html (date accessed: 21 July 2015)

Bevan, S., and John, P. (2016) 'Policy Representation by Party Leaders and Followers: What Drives UK Prime Minister's Questions? Government and Opposition, 51 (1), 59-83.

Borthwick, R. L. (1993) 'On the Floor of the House', in Mark N. Franklin and Philip Norton (eds.), Parliamentary Questions (Oxford: Clarendon Press), 73-103.

Bull, P. and Strawson, W. (2019) 'Can't Answer? Won't Answer? An Analysis of Equivocal Responses by Theresa May in Prime Minister's Questions', Parliamentary Affairs:

Forthcoming (https://doi.org/10.1093/pa/gsz003).

Bull, P. and Waddle, M. (2019) 'The Impact of Quoting Members of the Public in Prime Minister's Questions', Journal of Language Aggression and Conflict, 7 (1), $56-78$.

Bull, P. and Wells, P. (2012) ‘Adversarial Discourse in Prime Minister's Questions', Journal of Language and Social Psychology, 31 (1), 30-48.

Burnham, J., Jones, G.W. and Elgie, R. (1995) 'The Parliamentary Activity of John Major, 1990-94', British Journal of Political Science, 25 (4), 551-563.

Cameron, D. (2005) quoted in, 'Full Text of David Cameron's Victory Speech', The Guardian, 6 December 2005, http://www.theguardian.com/politics/2005/dec/06/toryleadership2005.conservatives3 (date accessed: 21 July 2015) 
Chester, D. N., and Bowring, N. (1962) Questions in Parliament (London: Oxford University Press)

Cumberbatch, G. Brown, B., and Skelton, J. (1992) 'The Implications of Parliamentary Broadcasting for Politicians', in Bob Franklin (ed.), Televising Democracies (London: Routledge), 203-17.

Dunleavy, P., Jones G. W., and O'leary B. (1990) 'Prime Ministers and the Commons: Patterns of Behaviour, 1868 to 1987', Public Administration, 68 (1), 123-139.

Dunleavy, P., Jones G. W., Elgie, R., and Fysh, P. (1993) 'Leaders, Politics and Institutional Change: The Decline of Prime Ministerial Accountability to the House of Commons, 18681990', British Journal of Political Science, 23 (3), 267-298.

Fast, N. J., Sivanathan, N., Mayer, N. D., and Galinsky, A. D. (2012), 'Power and Overconfident Decision-Making', Organizational Behavior and Human Decision Processes, 117 (2), 249-260.

Franklin, M. N. and Norton P. (eds.), (1993) Parliamentary Questions (Oxford: Clarendon Press).

Giddings, P., and Irwin, H. (2005) 'Objects and Questions', in Giddings, P. (ed.) The Future of Parliament (Basingstoke: Palgrave Macmillan), 67-77.

Griffith, J. A. G. and Ryle, M. (1989) Parliament (London: Sweet and Maxwell)

Hansard Society (2014) Audit of Political Engagement 11: The 2014 Report (London: Hansard Society)

Harris, S. (2001) 'Being Politically Impolite: Extending Politeness Theory to Adversarial Political Discourse, Discourse and Society, 12 (4), 451-472.

Irwin, H., Kennon, A., Natzler, D., and Rogers, R. (1993) 'Evolving Rules', in Mark N. Franklin and Philip Norton (eds.), Parliamentary Questions (Oxford: Clarendon Press), 2372.

Kelly, R. (2015) Prime Minister's Questions (London: House of Commons Library).

Keltner, D., Gruenfeld, D. H., and Anderson, C. (2003), 'Power, Approach and Inhibition', Psychological Review, 110 (2), 265-284.

Lovenduski, J. (2012) 'Prime Minister's Questions as Political Ritual', British Politics, 7 (4), 314-340.

Maner, J. K., Gailliot, M. T., Butz, D. A., and Peruche, M. (2007) 'Power, Risk, and the Status Quo: Does Power promote Riskier or More Conservative Decision Making?', Personality and Social Psychology Bulletin, 33 (4), 451-462.

Martin, S. (2011) Parliamentary Questions, the Behaviour of Legislators, and the Function of Legislatures: An Introduction, The Journal of Legislative Studies, 17 (3), 259-270. 
Martin, S. (2013) Parliamentary Questions, Comparative Assessment of Parliaments (CAP) Note (Albany, NY: State University of New York)

Murphy, J. (2014) '(Im)politeness during Prime Minister's Questions in the UK Parliament', Pragmatics and Society, 5 (1), 76-104.

Norton, P. (1993) 'Questions and the Role of Parliament', in Franklin, M. N. and Norton P. (eds.), (1993) Parliamentary Questions (Oxford: Clarendon Press).

Packenham, R. (1970) 'Legislatures and Political Development', in A. Kornberg and L. D. Musolf, (eds.) Legislatures in Developmental Perspective (Durham, NC: Duke University Press), 521-582.

Pfeffer, J. (2010) Power: Why Some People Have It - And Others Don't (New York: Harper Collins).

Salmond, R. (2014a) 'Parliamentary Question Times: How Legislative Accountability Mechanisms Affect Mass Political Engagement', The Journal of Legislative Studies, 20 (3), 321-341.

Salmond, R. (2014b) 'Robust and Partisan Parliamentary Events Like Prime Ministers Questions Increase Engagement with Politics', 21 May 2014, http://www.democraticaudit.com/?p=5065 (date accessed: 21 July 2015)

Shephard, M. (1999) Prime Minister's Question Time: Functions, Flux, Causes and Consequences, a Behavioural Analysis (Houston: University of Houston)

Waddle, M., and Bull, P. (2019) Curbing Their Antagonism: Topics Associated with a Reduction in Personal Attacks at Prime Minister's Questions, Parliamentary Affairs, gsz010, https://doi.org/10.1093/pa/gsz010 (date accessed: 13 June 2019).

Waddle, M., Bull, P., and Böhnke, J. R. (2019) "He is Just the Nowhere Man of British Politics": Personal Attacks in Prime Minister's Questions', Journal of Language and Social Psychology, 38 (1), 61-84.

Wiberg, M. ed. (1994) Parliamentary Control in the Nordic Countries: Forms of Questioning and Behavioural Trends (Jyväskylä: The Finnish Political Science Association)

YouGov (2015) 'Times RedBox Prime Minister's Question Time Survey Results' 16 January 2015 , https://d25d2506sfb94s.cloudfront.net/cumulus_uploads/document/fbxh6iftqi/Redbox_Result S 150115 PMQTs Website.pdf (date accessed: 21 July 2015) 


\section{Appendix 1}

\section{PM Targets Main Leader of the Opposition (Response Intended) (OL)}

\section{Tony Blair (PM)}

23 July 1997, cols. 948-949, https://www.parliament.uk/business/publications/hansard/commons/by-date/ (date accessed: $24 / 06 / 2019$ )

Mr. Hague: Waffling and wriggling will not get the Prime Minister out of the question. Let me remind him of what he said: "A Welsh Assembly means decisions about schools, hospitals and law and order can be taken here".

Why was that the Prime Minister's policy last Friday, when he was in Wales, but not this week, when he is in London? Let us get this straight. He said that the Scottish Parliament would be a parish council and then that it would not be. He promised to publish the devolution Bills before the referendums and then said that he would not. He said that a Welsh Assembly would run the police and now he says that it will not. Are not people entitled to be worried that these must be pretty ill-thought-out proposals if he cannot even understand them himself?

The Prime Minister: I repeat my answer for the third time. The Leader of the Opposition quoted one part of my remarks in relation to law and order and not the other. [Hon. Members: "Aah."] If he reads my comments, he will see that that is so. As to devolution more generally, the Conservative party has just agreed that there should be a Londonwide body, with an elected mayor, to oversee the governance of London. Let me quote the leader of Wandsworth council. [Hon. Members: "The question is about Wales."] Opposition Members do not want to hear it. He said that it was time that Londoners had a voice for London. If it is good enough for London, why is it not good enough for Wales?

\section{PM Targets Main Leader of the Opposition (Response Not Intended) (OL)}

\section{Gordon Brown (PM)}

11 July 2007, col. 1439, https://www.parliament.uk/business/publications/hansard/commons/by-date/ (date accessed: $24 / 06 / 2019)$

\section{Mr. Cameron:}

The Prime Minister is getting a bit ahead of himself, as the person in question is not even Lord Darzi yet. I asked a simple question. The author of the report says: "The days of the district general hospital... are over", and that we need "fewer, more advanced hospitals". What can that mean if not cuts in departments and closures in existing hospitals? 
The Prime Minister: It means more money for the national health service this year, next year and the year after-money that the opposition will not match. It means a proposal for 150 new polyclinics, which will mean that GPs will be able to undertake operations. It means an improvement in specialist care in London. It means this Government are prepared to finance the NHS.

If we are updating ourselves about Conservative party policy, let me remind the House that not only will the opposition not match us on health service spending, but they have just issued a report on the future of hospitals in which they say that, because of their funding mechanism, hospitals are at risk "of financial failure" and this will "entail risks to the assets necessary for the provision of essential national health services."

Who is closing hospitals - the Government or the opposition? It is the Conservative party.

PM Targets General Opposition, Including Other Party Leaders (Response Intended) $\underline{(\mathbf{O})}$

\section{Tony Blair (PM)}

11 June 1997, col. 1137, https://www.parliament.uk/business/publications/hansard/commons/by-date/ (date accessed: $24 / 06 / 2019)$

Q4. Mrs. Ray Michie: Does the Prime Minister agree with his colleagues both past and present who signed the Claim of Right based on the sovereignty of the Scottish people or does he, as was widely reported before the general election, still believe that sovereignty rests with him as an English Member of Parliament?

The Prime Minister: The simple fact is, as, indeed, the Constitutional Convention accepted, that ultimate sovereignty rests with the Westminster Parliament. Of course that is so.

Mrs. Ewing: No.

The Prime Minister: Well, it is actually there in the Constitutional Convention. In respect of the Claim of Right and sovereignty of the Scottish people, what could be better than giving them the sovereign right to decide in a referendum whether they want a Scottish Parliament? That is surely the sensible way to proceed. Having watched the debate with considerable interest over the past few months, I believe that the vast majority of people in Scotland, including the constituents of the hon. Member for Argyll and Bute (Mrs. Michie), are less interested in those types of constitutional intricacy than they are in seeing how the Scottish Parliament delivers better health, better education, better law and order services to the people. If we all concentrated on that, we would get a long way. 


\section{PM Targets General Opposition, Including Other Party Leaders (Response Not}

\section{Intended) (O)}

\section{Tony Blair (PM)}

18 June 1997, cols. 310-311, https://www.parliament.uk/business/publications/hansard/commons/by-date/ (date accessed: 24/06/2019)

Q9. Mr. Stevenson: Is it not a scandal that thousands of our children and young people are being taught in dilapidated buildings? Is it not a fact that that is a direct result of a deliberate policy of chronic neglect by the Conservative party when it was in government? Will my right hon. Friend confirm that under this Government this completely unacceptable situation will be dealt with as a matter of priority?

The Prime Minister: I can confirm that. Of course it is important that we begin to put right the damage done over a period of years. The plain fact of the matter is that the previous Government were one of the very few Governments anywhere to preside over a situation where the proportion of national income spent on education fell, although the social security and welfare bills rose enormously. It is precisely for that reason that we do not see additional expenditure on education as enough in itself. It must be accompanied by measures that reduce the huge and appalling burden of social and economic failure that is the product of the past 18 years. It is both those things going together that allows us to get as much money as possible into the areas of productive investment and to get us out of social failure. [Hon. Members: "Where from?"] How about by reducing the numbers of young people on the dole? That is where from.

\section{Appendix 2}

PM Appropriating Blame (Response Intended) (BPG)

\section{David Cameron (PM)}

23 June 2010, col. 286, https://www.parliament.uk/business/publications/hansard/commons/by-date/ (date accessed: $24 / 06 / 2019$ ) 
The Prime Minister: The point that the right hon. and learned Lady has got to address is who left us in this mess. Who left a budget deficit of $£ 155$ billion, with absolutely no proposals to deal with it? Who put forward- [ Interruption.]

\section{PM Appropriating Blame (Response Not Intended) (BPG)}

\section{Gordon Brown (PM)}

17 October 2007, col. 821, https://www.parliament.uk/business/publications/hansard/commons/by-date/ (date accessed: 24/06/2019)

The Prime Minister: My hon. Friend is absolutely right. There is a $£ 6$ billion black hole in the Conservatives' promises. They cannot afford to pay for their spending commitments and are back to where they were in 1992 - with more spending, lower taxes and less borrowing. Where did that end? It ended not only in Black Wednesday, but with 3 million people unemployed, public spending cuts and 15 per cent. mortgage rates. And the economic adviser to the Chancellor at the time is now the Leader of the Opposition.

\section{PM Criticising Opposition (Response Intended) (CO)}

\section{Theresa May (PM)}

02 November 2016, col. 882, https://www.parliament.uk/business/publications/hansard/commons/by-date/ (date accessed: $24 / 06 / 2019$ )

The Prime Minister: I am pleased to say that what we have seen under this Government is nearly half a million more disabled people actually in the workplace. My right hon. Friend the Secretary of State for Work and Pensions has launched a Green Paper on work, which is starting to look at how we can continue to provide and increase support for those who are disabled who want to get into the workplace. But the right hon. Gentleman started his question by asking me about the increase in the money that is being spent on housing benefit. If he thinks that the amount of money being spent on housing benefit is so important, why did he oppose the changes we made to housing benefit to reduce the housing benefit bill?

\section{PM Criticising Opposition (Response Not Intended) (CO)}

\section{Gordon Brown (PM)}

11 July 2007, col. 1439, https://www.parliament.uk/business/publications/hansard/commons/by-date/ (date accessed: $24 / 06 / 2019$ ) 
The Prime Minister: It means more money for the national health service this year, next year and the year after-money that the opposition will not match. It means a proposal for 150 new polyclinics, which will mean that GPs will be able to undertake operations. It means an improvement in specialist care in London. It means this Government are prepared to finance the NHS.

If we are updating ourselves about Conservative party policy, let me remind the House that not only will the opposition not match us on health service spending, but they have just issued a report on the future of hospitals in which they say that, because of their funding mechanism, hospitals are at risk "of financial failure" and this will "entail risks to the assets necessary for the provision of essential national health services." Who is closing hospitalsthe Government or the opposition? It is the Conservative party.

\footnotetext{
i Order Paper questions are those that have been tabled at least three days in advance and that are successfully selected from a random computer selection. The first MP to have a question selected is listed as Q1 and the Order Paper lists the first 15 questions that are selected. Not all 15 questions may be reached in the time allocated as the procedure as questions and PM replies have no set timing logic.

ii Supplementary questions are follow-up questions on the same topic. The Leader of the Opposition is typically granted most leeway on supplementary questions during PMQs.
} 